\title{
Impact of the COVID-19 pandemic on orthopaedic and trauma surgery training in Europe
}

\author{
Panayiotis D. Megaloikonomos ${ }^{1}$ (D) $\cdot$ Martin Thaler $^{2} \cdot$ Vasilios G. Igoumenou $^{3} \cdot$ Tommaso Bonanzinga $^{4}$. \\ Marko Ostojic ${ }^{5}$ - André Faria Couto ${ }^{6} \cdot$ Jasmin Diallo $^{7} \cdot$ Ismail Khosravi $^{2}$
}

Received: 28 June 2020 / Accepted: 16 July 2020 / Published online: 21 July 2020

(C) SICOT aisbl 2020

\begin{abstract}
Purpose This study aimed to evaluate the impact of the coronavirus disease 2019 (COVID-19) pandemic on orthopaedic and trauma surgery training in Europe by conducting an online survey among orthopaedic trainees.

Methods The survey was conducted among members of the Federation of Orthopaedic and Trauma Trainees in Europe (FORTE). It consisted of 24 questions (single-answer, multiple-answer, Likert scales). Orthopaedic trainees' demographic data (six questions), clinical role changes (four questions), institutional changes due to the COVID-19 pandemic (nine questions), and personal considerations (five questions) were examined.

Results Three hundred and twenty-seven trainees from 23 European countries completed the survey. Most trainees retained their customary clinical role (59.8\%), but a significant number was redeployed to COVID-19 units (20.9\%). A drastic workload decrease during the pandemic was reported at most institutions. Only essential activities were performed at $57.1 \%$ of institutions and drastic disruptions were reported at $36.0 \%$. Of the respondents, $52.1 \%$ stated that faculty-led education was restricted and $46.3 \%$ pursued self-guided learning, while $58.6 \%$ stated that surgical training was significantly impaired. Concerns about the achievement of annual training goals were expressed by $58.2 \%$ of the participants, while $25.0 \%$ anticipated the need for an additional year of training.

Conclusions The SARS-CoV-2 pandemic significantly affected orthopaedic and trauma training in Europe. Most trainees felt the decrease in clinical, surgical, and educational activities would have a detrimental effect on their training. Many of them consulted remote learning options to compensate training impairment, stating that after the COVID-19 pandemic electronic educational approaches may become more relevant in future.
\end{abstract}

Keywords COVID-19 $\cdot$ SARS-CoV-2 $\cdot$ Pandemic $\cdot$ Orthopaedic training $\cdot$ Federation of Orthopaedic and Trauma Trainees in Europe

Electronic supplementary material The online version of this article (https://doi.org/10.1007/s00264-020-04742-3) contains supplementary material, which is available to authorized users.

Panayiotis D. Megaloikonomos pdmeg@med.uoa.gr

1 First Department of Orthopaedics, National and Kapodistrian University of Athens, School of Medicine, ATTIKON University Hospital, 1 Rimini Street, 12462 Haidari, Athens, Greece

2 Department of Orthopaedic Surgery, Medical University of Innsbruck, Innsbruck, Austria

3 Spine Center Stuttgart, Diakonie-Kinikum Stuttgart, Stuttgart, Germany
4 Department of Biomedical Sciences, Humanitas University, Milan, Italy

5 Department of Orthopaedics, University Hospital Mostar, Mostar, Bosnia and Herzegovina

6 Department of Orthopaedics, Centro Hospitalar São João, Porto, Portugal

7 Department of Orthopaedics, Langenthal Hospital, Langenthal, Switzerland 


\section{Introduction}

In December 2019, the coronavirus disease 2019 (COVID-19) broke out in Wuhan, the capital city of Hubei Province in China [1]. The cause of the disease was a highly contagious novel coronavirus (SARS-CoV-2) that rapidly spread around the world and in March 2020 was declared a global pandemic by the World Health Organization (WHO) [2]. To date, nearly 8.7 million people have been diagnosed positive for SARSCoV-2 and almost 462,000 people have died from the disease worldwide [2]. A monumental international collaboration against the pandemic and a rapid dissemination of emerging scientific evidence were observed, with symptoms, radiological and pathological findings, and other characteristics of the disease being described [3].

Europe rapidly became a serious epicentre of the COVID19 pandemic, with the control of virus spread becoming the singular focus of most European countries [4]. The high infectivity rate forced governments to implement socioeconomic measures such as confinement, suspension of business operations, and reallocation of resources. Additionally, this rapidly evolving emergency overwhelmed the existing healthcare systems which in most cases were reorganized to cope with the crisis. Medical specialties were impacted in different ways. Internal medicine, anaesthesia, and intensive care physicians stepped into the "frontline" to manage COVID-19 patients, working after hours to meet the increasing demand. Surgeons had to limit their surgical practice to essential procedures or they were deployed to fields outside their specialties [5].

Orthopaedic practice could not remain unaffected under these unforeseen circumstances. Non-urgent consultations and many surgical procedures were cancelled or postponed. Elective surgery in many institutions were suspended, and the overall orthopaedic case volume dropped dramatically to minimize the virus spread and reserve and reallocate resources in healthcare personnel (nurses, anaesthesiologists), medical equipment (personal protective equipment, ventilators), and beds [6]. In Europe, a drastic cutback in arthroplasty and arthroscopy procedures was documented [7, 8], and the frequency of trauma cases decreased during the COVID-19 period due to the "stay at home" policy [9].

This healthcare crisis had significant consequences not only for patients and surgeons but also for orthopaedic trainees [10]. It is easy to speculate that the limited clinical and surgical exposure, the suspension of in-hospital didactic activities, and the cancellation of most scientific meetings would considerably affect orthopaedic training. Some authors highlighted this issue in other surgical specialties $[11,12]$. However, to the best of our knowledge, the real ramifications of the crisis for orthopaedic education in Europe are largely unknown.

In this study, we assessed the impact of the COVID-19 pandemic on orthopaedic training by conducting an online survey of the members of the Federation of Orthopaedic and Trauma Trainees in Europe (FORTE). This European society encompasses orthopaedic residents and young orthopaedic surgeons in training. It was founded in 2005 , and since then has acted as a forum for its members, having as the main goal the promotion of education [13].

\section{Materials and methods}

We conducted an online survey for the members of FORTE. Institutional review board approval was deemed unnecessary for this study, as the survey was anonymous and no patient or respondent personal data were included. Data were collected using SurveyMonkey (https://www.surveymonkey.com, Portland, OR), an online data collection program. The survey consisted of 24 questions with single-answer, multiple-answer, and Likert scales. Six questions documented demographic features. Trainees' role changes in response to COVID-19 were examined in four questions. Institutional changes and their influence on participants' daily practice and training were evaluated in nine questions, while personal opinions and personal considerations were collected in five questions (Appendix).

In the demographics section of the survey, the country of practice was recorded and a matrix of multiple-response options examined the type of institution the participants were working at, their specific role, and their year of postgraduate training.

Redeployment of orthopaedic trainees in COVID-19 units was recorded. We included items to investigate any applied precautions, like virus testing for doctors and specific COVID-19 training. Leave for self-isolation or due to infection was also documented.

We investigated the institutional changes that impacted everyday practice or training; considering patient care, diagnostic examinations, surgical procedures, research, and teaching. Delays in qualification, fellowship options, and regular department meetings were also examined.

Additionally, the orthopaedic trainees were asked to provide their perception of the importance of different educational approaches. Among others, these included lectures, hospital rounds, orthopaedic courses, cadaveric labs, scientific meetings, e-learning, and virtual reality learning. They were also asked to anticipate potential future changes considering training opportunities.

A link to the survey was sent by email to the members of FORTE on May 28, 2020, and every second day a reminder was also sent to improve the response rate. The trainees were invited to complete the survey within 15 days and it was finally closed on June 11, 2020. All data gathered from the online database were calculated as frequencies and percentages. 


\section{Results}

A total of 327 orthopaedic and trauma trainees, from 23 European countries, participated in this survey. Of the surveyed trainees, $79.5 \%$ were males and $20.5 \%$ females. Most of them were between 30 and 35 years old $(49.0 \%)$, and $26.3 \%$ were younger and $24.7 \%$ older than this age group. Of the participants, $45.3 \%$ were working in university hospitals, $44.7 \%$ in non-university public hospitals, and only a minority in private institutions. A majority of them were residents $(70.3 \%)$ in different years of training. Post-residency trainees/fellows accounted for $23.9 \%$ (Table 1).

Of the trainees, $59.8 \%$ retained their clinical role in the orthopaedic department, but $20.9 \%$ were redeployed to nonorthopaedic COVID-19 units (Table 2). Regarding their occupational health, a majority of them were not examined for SARS-CoV-2 at their institution (65.9\%). Of those tested (34.1\%), a positive result was reported in $2.2 \%$. Of the participants, $47.1 \%$ did not leave their duties for self-isolation or due to infection. The rest reported one (11.1\%), two (17.2\%), three (13.1\%), and even more weeks (11.9\%) of absence for such reasons. No specific COVID-19 training was provided to most of the orthopaedic trainees $(60.3 \%)$.

During the pandemic, the institutions of $57.1 \%$ of the responders allowed only essential patient visits and emergency surgical procedures (fracture, infection, tumour patients), while $36.0 \%$ underwent drastic disruptions (Fig. 1). Trainees' on call activity, exposure to patient care, and participation in surgical operations were detrimentally impacted (Fig. 2). Regarding research activity, a diversity of responses was collected. Some participants found it was decreased (36.1\%), others increased (27.1\%), and others unchanged (26.6\%). Reduced teaching duties were also reported by approximately $56.6 \%$ of the participants (Fig. 2). With regard to remote working from home, $38.9 \%$ said this was not an option for residents and $14.8 \%$ that this could not apply to fellows. Most participants agreed that this was reserved only for e-learning or virtual learning (41.8\%), while others stated that this could only apply to research $(28.3 \%)$. Nevertheless, $16.4 \%$ stated that remote working was an option for providing medical care via telemedicine.

Table 1 Participants' level of training

\begin{tabular}{ll}
\hline Level of training & Participants (\%) \\
\hline First year resident & 12.2 \\
Second year resident & 7.0 \\
Third year resident & 10.1 \\
Fourth year resident & 10.4 \\
Fifth year resident & 10.1 \\
Final year resident & 20.5 \\
Post-residency training/fellowship & 23.9 \\
Other (intern, PhD student, researcher) & 5.8 \\
\hline
\end{tabular}

Faculty-led education was limited in most cases (52.1\%) during the COVID-19 period. Surgical education, namely preoperative planning, execution of operations, and post-operative care, was significantly impaired, as per $49.2 \%, 58.6 \%$, and $46.7 \%$ respectively of the surveyed participants. Clinical education at the patient's bedside was also impaired (56.0\%), but remote clinical learning increased (55.3\%) (Fig. 3).

The majority $(56.6 \%)$ of the respondents stated that all national and international fellowship options were suspended, while $23.0 \%$ reported that only international fellowships were interrupted. Regular orthopaedic department meetings continued with precautions for $34.8 \%$ of the respondents. Only selected trainees (e.g. on call) were allowed to attend (27.1\%), whereas $19.3 \%$ stated that they were exclusively held online via videoconference.

Significant concerns about the achievement of annual training goals were voiced by $58.2 \%$ of the participants, while $18.4 \%$ of them stated that this would definitely be impossible. Of the respondents, $45.5 \%$ believed that they will not acquire the expected practical skills, $45.1 \%$ that they will not complete their logbook, and $15.6 \%$ that their final exams will be postponed. One-fourth of the respondents were afraid of losing a trimester, semester, or even a year of specialization training, believing at the same time that an additional year of appropriate training will be necessary. However, the majority (61.1\%) believe they will finish their rotation as planned.

On a 1 to 5 scale $(1=$ not important, $5=$ very important $)$, participants described their perceptions about the importance of different educational approaches. Travelling for fellowship training was considered the most important approach (mean score, 4.3), followed by institutional cadaveric courses (4.2) and travelling for orthopaedic learning courses (4.1). Core curriculum lectures obtained 4.0 points, international and national meetings 3.9 points, and Web-based video platforms 3.8 points. The lowest score was given to grand rounds (3.5). Rating the importance of educational approaches in the future compared with present, higher scores to electronic education opportunities were found; virtual reality surgical simulators (4.2 vs 3.7$)$, Web-based video platforms ( 4.2 vs 3.8 ), e-learning (4.1 vs 3.7), and podcasts/webinars (4.1 vs 3.6), highlighting their emerging importance (Fig. 4).

Altogether, $54.5 \%$ of the respondents stated that orthopaedic training will be negatively affected by the COVID-19 crisis, while $21.3 \%$ postulated that there are multiple possibilities to achieve a better education. Finally, most of participants (75.4\%) believed that providing healthcare via telemedicine will become more relevant in the future, due to the COVID-19 pandemic.

\section{Discussion}

The impact of the COVID-19 crisis on orthopaedic and trauma training had three components. First, a considerable 
Table 2 Trainees' clinical role changes due to COVID-19
Have you been, are you currently working or will you be soon working in COVID-19 units or with COVID-19 patients?

\begin{tabular}{|c|c|}
\hline Yes, I have been/am/will be assigned to non-orthopedic patients in a COVID-19 unit & 20.9 \\
\hline Yes, I have been/am/will be assigned to orthopedic patients in a COVID-19 unit & 7.8 \\
\hline $\begin{array}{l}\text { Yes, I have been/am/will be assigned to non-orthopedic patients but not working in a } \\
\text { COVID-19 unit }\end{array}$ & 3.3 \\
\hline $\begin{array}{l}\text { Yes, I have been/am/will be assigned to orthopedic patients with COVID-19 but not } \\
\text { working in a COVID-19 unit }\end{array}$ & 8.2 \\
\hline $\begin{array}{l}\text { No, I have continued my current clinical role/not been knowingly working with } \\
\text { COVID-19 patients }\end{array}$ & 59.8 \\
\hline
\end{tabular}

number of trainees were redeployed to non-orthopaedic sectors during the crisis, spending their training time on nonorthopaedic medical or even non-medical activities. Second, the general reduction in orthopaedic clinical and surgical volume implies that training had to be forcibly disrupted, altered, or prolonged. Third, education had to evolve radically, by implementing and incorporating modern teaching modalities, such as e-learning, webinars, and virtual simulators.

In our survey, most trainees stated that they did not work with COVID-19 patients. However, $20.9 \%$ of the respondents were redeployed and for a certain time period were responsible for non-orthopaedic patients in COVID-19 units, with a few $(3.3 \%)$ even assigned to non-orthopaedic patients outside a COVID-19 unit. Similar findings were reported in a survey of young arthroplasty surgeons [14]; of the respondents $75 \%$ continued their work as orthopaedic surgeons, whereas $7 \%$ were redeployed to the ICU for COVID-19 patients, and another $18 \%$ to the emergency room/non-ICU units. Despecialization and redeployment may address urgent service needs, but education plans are disrupted in such situations, posing future issues with board requirements [15]. Redeployment in conjunction with safety issues may give rise to a rather troubling situation. According to our survey, $60.3 \%$ of trainees did not receive specific COVID-19 training and $65.9 \%$ were not tested for COVID-19. Fighting on the frontline against SARS-CoV-2, sometimes with limited availability of personal protective equipment, poses a vital risk for clinicians [16-18]. This risk may be further increased when redeployed and working outside a clinician's specialty zone, where errors are likely to occur because of the lack of competency $[16,19,20]$. Limiting trainees' exposure, keeping them safe, and preventing their discomfort as a result of this psychological burden should be of utmost importance.

For the majority of respondents, overall orthopaedic activity was limited to various degrees in comparison with the preCOVID-19 era. Regarding surgical volume and nature of surgery performed during the COVID-19 period, an almost complete disruption of elective surgery was reported, and only $5.4 \%$ of the trainees responded that all routine activities and surgery continued as usual, while more than half $(57.1 \%)$ stated that only emergency procedures were performed. This is in accordance with other studies reporting a dramatic decline in elective surgery [8, 21, 22]. In a survey of members of the European Hip Society (EHS) and the European Knee Associates (EKA), $68.4 \%$ of surgeons responded that elective inpatient procedures were no longer being performed, and $68 \%$ reported that all outpatient procedures were cancelled, while only $0.7 \%$ reported no changes at their department [8]. An average reduction of $49.4 \%$ in operating room capacity was also reported by a German study [21]. This unavoidably had a significant impact on training, as clinical and most importantly surgical exposure are the most important vectors in developing orthopaedic skills. In connection with this, we were able to compare our findings mainly with studies from other specialties. The majority of
Fig. 1 Institutional changes as a result of the COVID-19 pandemic

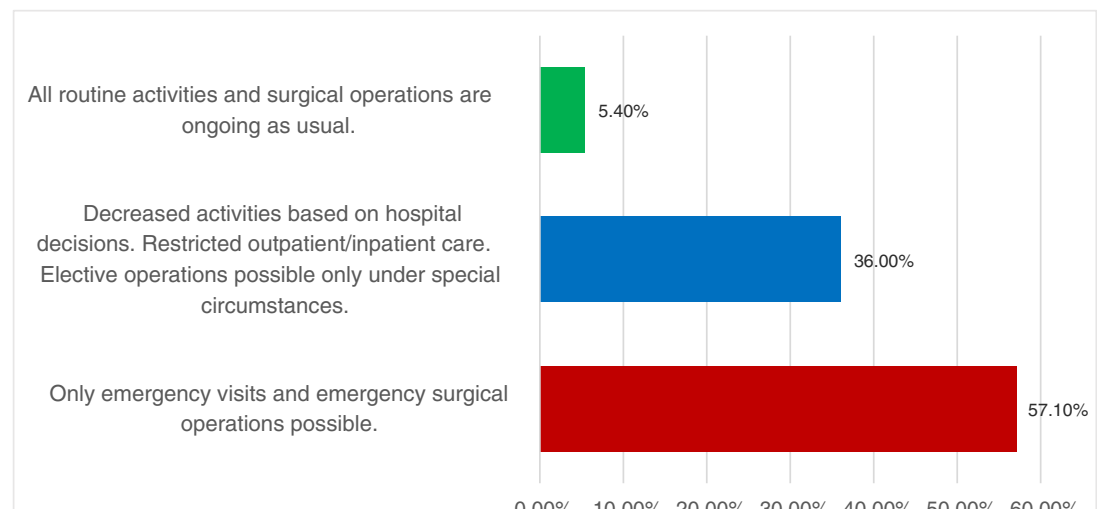

$0.00 \% \quad 10.00 \% \quad 20.00 \% \quad 30.00 \% \quad 40.00 \% \quad 50.00 \% \quad 60.00 \%$ 


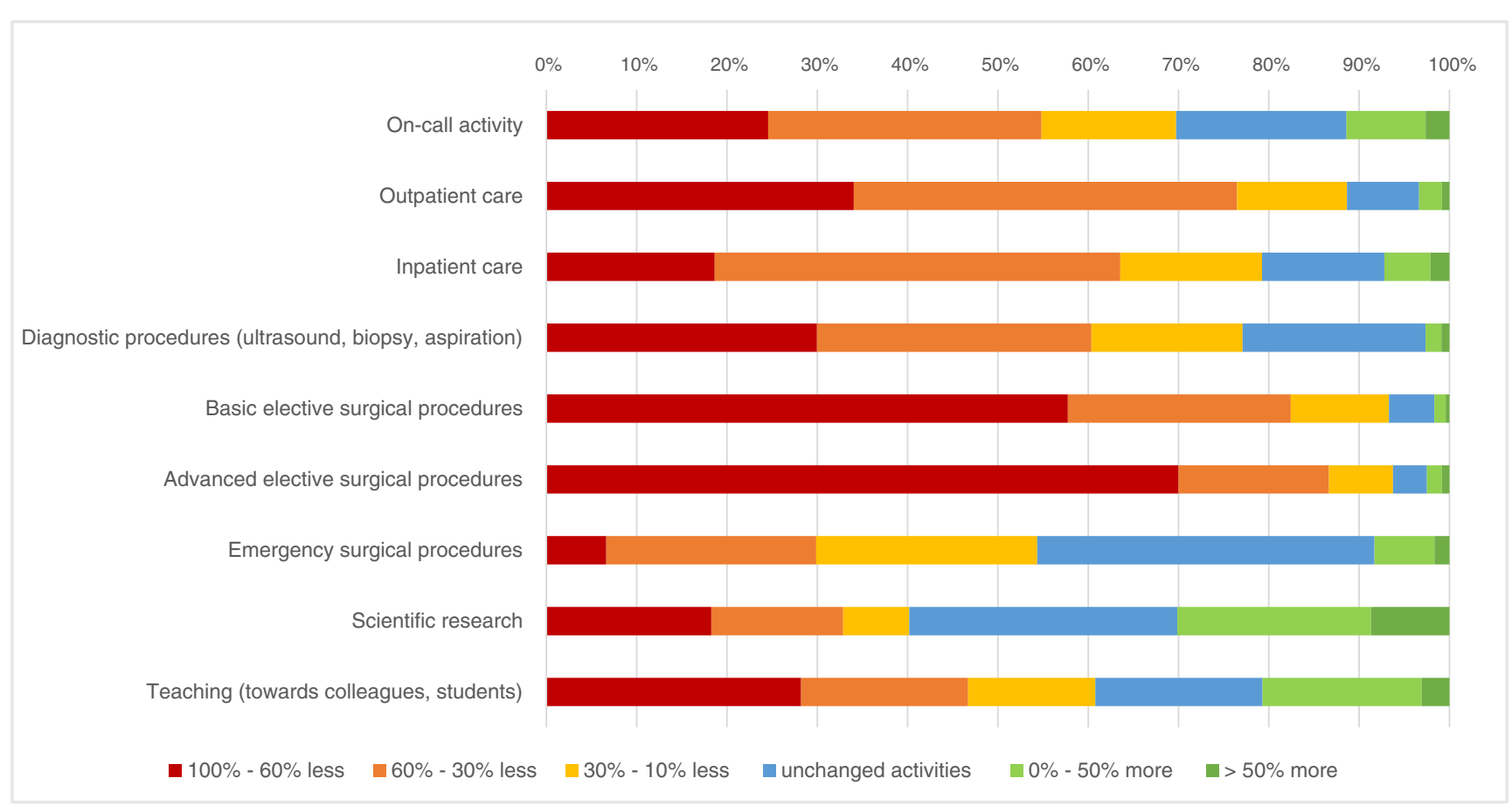

Fig. 2 Changes in trainees' activities during the COVID-19 pandemic compared with the period before

participants $(84.5 \%)$ in a study examining the training of gastroenterologists reported that the COVID-19 outbreak significantly impacted their training. The crisis led to a major training gap, due to trainees' redeployment and the reduced volume of activities within their specialty [23]. In a similar study of neurosurgery training, the authors also reported a volume decrease and that many outpatient visits had been transitioned to telemedicine, decreasing resident exposure to outpatients [24]. Additionally, other authors reported that urology residents will not meet minimum case requirements because of COVID-19, while double-scrubbing in the operating room was significantly reduced, thus negatively affecting their surgical exposure [25].

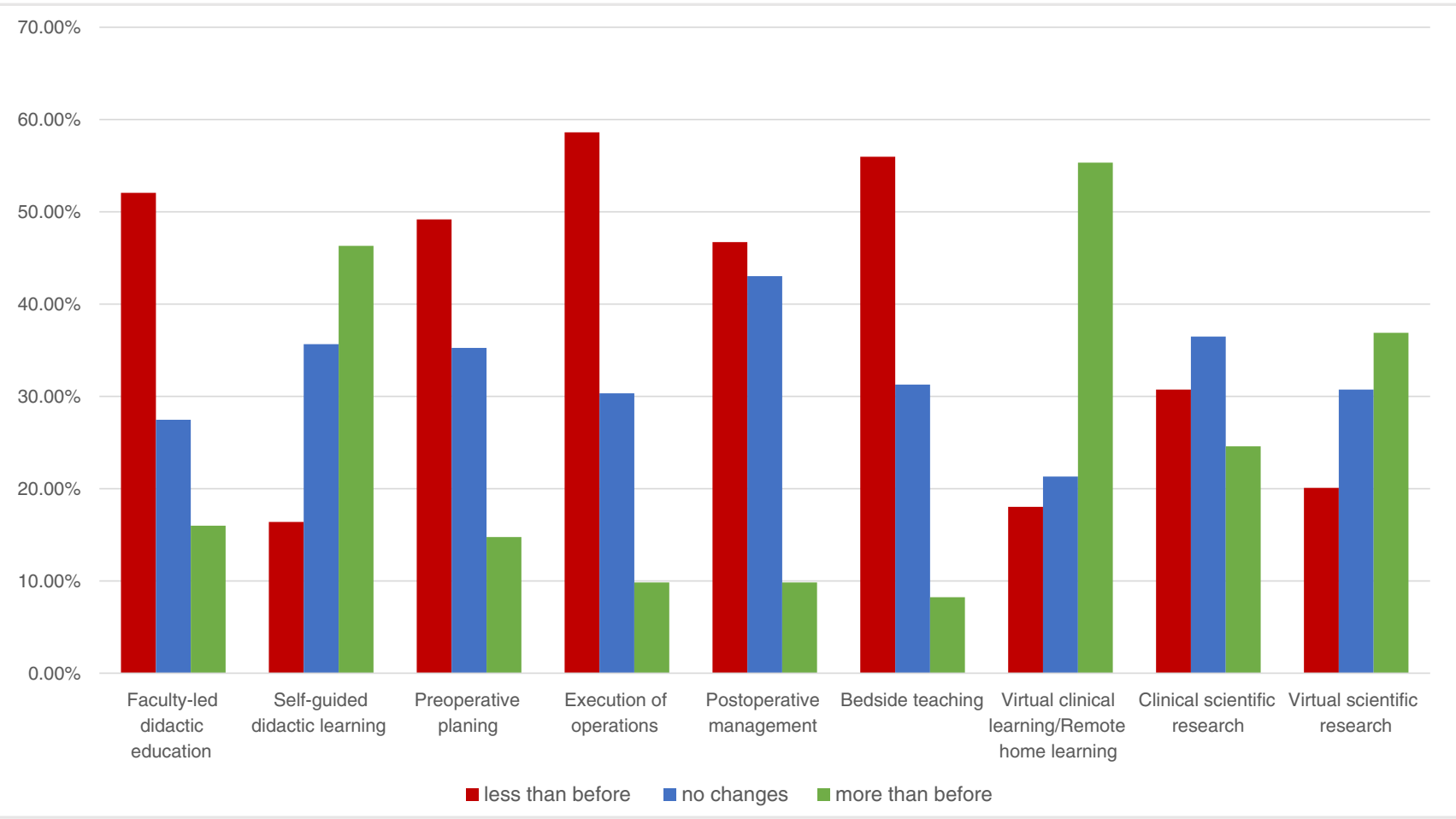

Fig. 3 Changes in trainees' training during the COVID-19 pandemic compared with the period before 
Institutional: Core curriculum lectures (didactic)

Institutional: Grand rounds/Visiting professor

Institutional: Journal club/Research project presentations/Textbooks

Institutional: Cadaveric training

Travel for group education: International meetings/National meetings

Travel for group education: Regional meetings/Local meetings

Travel for group education: Orthopaedic learning courses

Travel for group education: Fellowships/Internships

Electronic education: E-learning/Electronic textbooks

Electronic education: Web-based video platforms

Electronic education: Podcasts/Online blogs/Webinars

Electronic education: Virtual reality learning/Surgical simulators

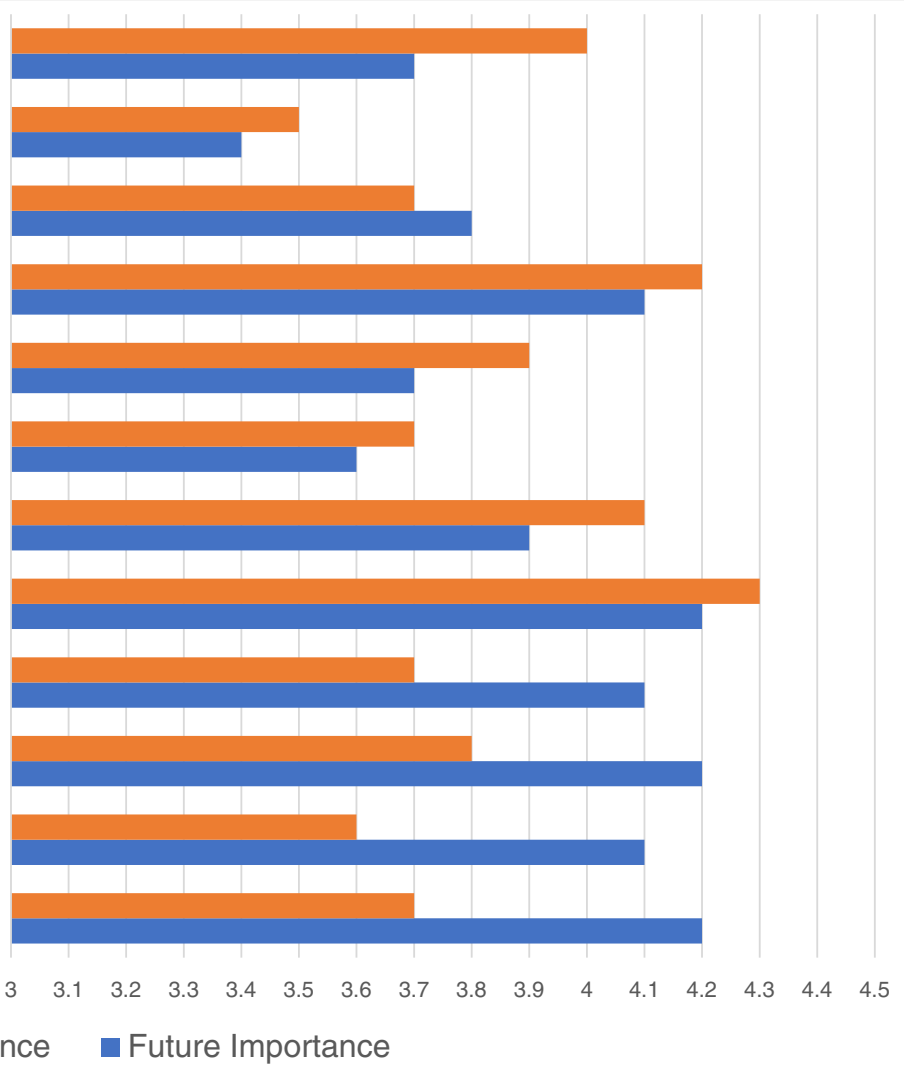

Fig. 4 Participants' perception about current and future importance of different educational approaches (mean scores of a $1-5$ scale: $1=$ not important, $5=$ very important)

In general, diverse responses were collected regarding research activity during the pandemic. Some participants postulated that it was decreased $(36.1 \%)$; others that it was increased $(27.1 \%)$. Specifically, clinical research was reported to be decreased by $30.7 \%$, increased by $24.6 \%$, and remained the same for $36.5 \%$ of respondents. These findings agree with those of other studies reporting an increase in resident research in $26 \%$ of training programmes and a decrease in $22 \%$ of them [25], suggesting that trainees' increased off-service time led to increased resident productivity in terms of clinical research activities [26].

As expected, the surgical aspect of education in the preoperative, intra-operative, and post-operative settings was limited for half of the respondents, which is of course a result of the above-discussed significant decrease in surgery overall. In terms of didactic education, the teaching duties of residents were reduced, and the traditional teaching modalities, including faculty-led didactic education and bedside teaching, were abandoned as well. However, more than half of the participants claimed that remote clinical learning increased and most of them stated that academic education in virtual scientific research was the same or even increased. These findings were important for two reasons. First, they document the problem that arose in orthopaedic surgical training, which is no other than the limitation of core surgical education in operating theatres. Second, they provide a glimpse into the new era of education, which is the implementation of new technologies for the training of residents and fellows. In fact, a survey of programme directors of neurosurgical residency programmes in the USA showed that nearly all programmes were conducting grand rounds, morbidity and mortality conferences, and didactic lectures using teleconferencing software, either live-streamed, led by faculty or residents, prerecorded, or also even sourced from outside institutions [26]. In a similar survey of urology training programmes, $48 \%$ of programmes reported that didactics were negatively impacted by COVID19. They had all started using video-conferencing and many of them were planning to continue offering virtual didactics in the future, as well [26].

Our survey attempted to further investigate the insight of residents and fellows into the achievement of personal training goals and into the future of education per se. Six out of ten orthopaedic trainees fear that they will not reach their competency goals within the training year, primarily due to nonachievement of practical and surgical skills (logbook). Other potential delays were the total waste of a training period and the suspension of final specialty exams. This probably led many of them to believe they may need an additional year of appropriate training. This fear is widely expressed in the related literature. Ramos et al. [27] reported that the overall 
training of spine surgery fellows could be compromised, having lost three months of elective surgery experience, unless measures to address the areas of weakness are taken. In the same regard, many arthroplasty surgeons in training do not feel adequately trained and confident to move forward in their careers [14].

There is no doubt that education has to go new ways. But which direction should it take? According to respondents in the current survey, the most important components of orthopaedic training to date have been fellowships, cadaveric training, and orthopaedic learning courses, with grand rounds being regarded as less significant. However, the future perspective of traditional training methods was retained only for cadaveric training and fellowships - the practical components of training, indeed. Interestingly enough, higher scores were given to all electronic education opportunities; including virtual reality surgical simulators, Web-based video platforms, elearning, and podcasts/webinars, thus highlighting the need for their further development. Additionally, the vast majority of our participants (75.4\%) believed that the COVID-19 pandemic will cause the provision of healthcare via telemedicine to become more relevant in future, despite the fact that telemedicine during the pandemic was rather limited and reserved mostly for research and e-learning. These findings imply that residency and fellowship programmes must consider unique and novel avenues of practicing and learning.

Weekly meetings, courses, and scientific conferences, that previously took place in person, may be held in virtual spaces [28]. Years ago, Palan et al. [29] reported their experience with virtual learning platforms and virtual journal clubs to help optimize resident time spent away from hospital. The authors found a number of unique strengths relative to a traditional in person learning format, including the ability to revisit the digitally recorded session, ease of access to both clinical material and key articles, and the ability to connect from different geographic regions. In the same setting, large national and regional orthopaedic meetings may feel pressure to move to more virtual platforms [30]. Many of these developing platforms have interactive features - such as chatting and messaging - where listeners can actively interact with the presenters, no different from traditional question and answer periods. The difficulty involved in placing all scientific presentations in the available lecture space can now belong to the past as virtual 3D environment platforms have already been developed [30].

But what about residents' and trainees' greatest concern: surgical skills? The answer may be the implementation of surgical simulators and virtual reality platforms in orthopaedic surgical training. Before COVID-19, there had already been a push to improve orthopaedic surgical skills training outside the operating room in order to meet the demands of restricted hours, patient safety concerns, and the growing number of technically challenging procedures [31]. Hence, simulators for cadaveric dissection or surgical procedures such as arthroscopy or arthroplasty have been developed [28, 30]. However, even though this technology may help trainees learn the basic motions of surgical performance, they do not acquire the necessary tactile feedback for advanced skill development [30]. The pandemic environment will most probably force us to find a solution and will act as a catalyst for improving and implementing these platforms in orthopaedic training.

Finally, approximately one-fourth of our respondents believe that orthopaedic and trauma surgery training will remain unchanged, while half of all trainees are pessimistic and believe that training will be worse. There is, however, an optimistic $21.3 \%$, who believe that there is now an opportunity to improve education. We believe that all efforts should be targeted at this optimistic conception and that technology can be harnessed to facilitate this direction. Medical education and science should be continued and should not be frightened by the crisis; it is the responsibility of a medical doctor to provide medical information and convey knowledge despite casualties [32].

The present study has several limitations inherent to all survey-based research. First, the respondents came from various countries that maintain different strategies toward the pandemic and that were experiencing the pandemic at different levels of severity. Second, it is possible that novel educational interventions being used at centres are not captured here. Third, many questions were set up as multiple-choice questions to simplify responding. Because this strategy can miss some of the nuances of open-ended answers, we included areas for free-text response to capture any additional response details. As a result, some programmes may use interventions that were missed. However, our sample consisted of orthopaedic residents and trainees from almost every European country, rendering it a rather representative survey group that can robustly depict the current state of orthopaedic training in Europe.

In conclusion, it is clear that the SARS-CoV-2 pandemic significantly affected orthopaedic and trauma training in Europe. A considerable number of trainees were redeployed to non-orthopaedic sectors during the crisis, where they spent their training time other than on orthopaedic activities. In addition, the reduction in surgical volume disrupted training by altering its nature or prolonging it, and these changes seem to be worrying trainees. Under these circumstances, education had to adapt and evolve and must continue to do so. In the process, it leaves behind traditional teaching methods and implements modern ones, such as e-learning, Webbased video platforms, webinars, and virtual reality learning and surgical simulators.

Acknowledgements We would like to thank FORTE secretary Ms. Clara Alves for her help in this study. 


\section{Compliance with ethical standards}

Conflict of interest The authors declare that they have no conflict of interest.

\section{References}

1. Zhu N, Zhang D, Wang W, Li X, Yang B, Song J, Zhao X, Huang B, Shi W, Lu R, Niu P, Zhan F, Ma X, Wang D, Xu W, Wu G, Gao GF, Tan W, China Novel Coronavirus I, Research T (2020) A novel coronavirus from patients with pneumonia in China, 2019. N Engl J Med 382(8):727-733. https://doi.org/10.1056/NEJMoa2001017

2. WHO (2020) Coronavirus disease (COVID-19) pandemic. https:// www.who.int/emergencies/diseases/novel-coronavirus-2019. Accessed 21/06/2020

3. Vannabouathong C, Devji T, Ekhtiari S, Chang Y, Phillips SA, Zhu M, Chagla Z, Main C, Bhandari M (2020) Novel coronavirus COVID-19: current evidence and evolving strategies. J Bone Joint Surg Am 102(9):734-744. https://doi.org/10.2106/JBJS.20. 00396

4. Steffens I (2020) A hundred days into the coronavirus disease (COVID-19) pandemic. Euro Surveill 25(14). https://doi.org/10. 2807/1560-7917.ES.2020.25.14.2000550

5. Seah KM (2020) Redeployment in COVID-19: old dogs and new tricks. Emerg Med J: EMJ. https://doi.org/10.1136/emermed-2020210052

6. Mavrogenis AF, Quaile A, Scarlat MM (2020) The virus crisis affects orthopaedic surgery and scientific activities worldwide. Int Orthop 44(5):813-817. https://doi.org/10.1007/s00264-02004557-2

7. Liebensteiner MC, Khosravi I, Hirschmann MT, Heuberer PR, Board of the AGASoA, Joint S, Thaler M (2020) Massive cutback in orthopaedic healthcare services due to the COVID-19 pandemic. Knee Surg Sports Traumatol Arthrosc 28(6):1705-1711. https:// doi.org/10.1007/s00167-020-06032-2

8. Thaler M, Khosravi I, Hirschmann MT, Kort NP, Zagra L, Epinette JA, Liebensteiner MC (2020) Disruption of joint arthroplasty services in Europe during the COVID-19 pandemic: an online survey within the European Hip Society (EHS) and the European Knee Associates (EKA). Knee Surg Sports Traumatol Arthrosc 28(6): 1712-1719. https://doi.org/10.1007/s00167-020-06033-1

9. Hernigou J, Morel X, Callewier A, Bath O, Hernigou P (2020) Staying home during "COVID-19" decreased fractures, but trauma did not quarantine in one hundred and twelve adults and twenty eight children and the "tsunami of recommendations" could not lockdown twelve elective operations. Int Orthop. https://doi.org/ 10.1007/s00264-020-04619-5

10. An TW, Henry JK, Igboechi O, Wang P, Yerrapragada A, Lin CA, Paiement GD (2020) How are orthopaedic surgery residencies responding to the COVID-19 pandemic? An assessment of resident experiences in cities of major virus outbreak. J Am Acad Orthop Surg. https://doi.org/10.5435/JAAOS-D-20-00397

11. Pang KH, Carrion DM, Rivas JG, Mantica G, Mattigk A, Pradere B, Esperto F, European Society of Residents in U (2020) The impact of COVID-19 on European health care and urology trainees. Eur Urol. https://doi.org/10.1016/j.eururo.2020.04.042

12. Zingaretti N, Contessi Negrini F, Tel A, Tresoldi MM, Bresadola V, Parodi PC (2020) The impact of COVID-19 on plastic surgery residency training. Aesthet Plast Surg. https://doi.org/10.1007/ s00266-020-01789-w

13. Madanat R, Makinen TJ, Ryan D, Huri G, Paschos N, Vide J committee $\mathrm{Fw}(2017)$ The current state of orthopaedic residency in 18
European countries. Int Orthop 41(4):681-687. https://doi.org/10. 1007/s00264-017-3427-0

14. Culp BM, Frisch NB (2020) COVID-19 impact on young arthroplasty surgeons. J Arthroplast. https://doi.org/10.1016/j.arth. 2020.04.058

15. Dedeilia A, Sotiropoulos MG, Hanrahan JG, Janga D, Dedeilias P, Sideris M (2020) Medical and surgical education challenges and innovations in the COVID-19 era: a systematic review. In Vivo 34(3 Suppl):1603-1611. https://doi.org/10.21873/invivo.11950

16. Ambrosio L, Vadala G, Russo F, Papalia R, Denaro V (2020) The role of the orthopaedic surgeon in the COVID-19 era: cautions and perspectives. J Exp Othop 7(1):35. https://doi.org/10.1186/s40634020-00255-5

17. Guo X, Wang J, Hu D, Wu L, Gu L, Wang Y, Zhao J, Zeng L, Zhang J, Wu Y (2020) Survey of COVID-19 disease among orthopaedic surgeons in Wuhan, People's Republic of China. J Bone Joint Surg Am 102(10):847-854. https://doi.org/10.2106/JBJS.20. 00417

18. Jella TK, Acuna AJ, Samuel LT, Jella TK, Mroz TE, Kamath AF (2020) Geospatial mapping of orthopaedic surgeons age 60 and over and confirmed cases of COVID-19. J Bone Joint Surg Am Vol 102(12):1022-1028. https://doi.org/10.2106/JBJS.20.00577

19. Dunham AM, Rieder TN, Humbyrd CJ (2020) A bioethical perspective for navigating moral dilemmas amidst the COVID-19 pandemic. J Am Acad Orthop Surg 28(11):471-476. https://doi.org/10. 5435/JAAOS-D-20-00371

20. Sarpong NO, Forrester LA, Levine WN (2020) What's important: redeployment of the orthopaedic surgeon during the COVID-19 pandemic: perspectives from the trenches. J Bone Joint Surg Am 102(12):1019-1021. https://doi.org/10.2106/JBJS.20.00574

21. Haffer H, Schomig F, Rickert M, Randau T, Raschke M, Wirtz D, Pumberger M, Perka C (2020) Impact of the COVID-19 pandemic on orthopaedic and trauma surgery in university hospitals in Germany: results of a nationwide survey. J Bone Joint Surg Am. https://doi.org/10.2106/JBJS.20.00756

22. Wong JSH, Cheung KMC (2020) Impact of COVID-19 on orthopaedic and trauma service. J Bone Joint Surg 00-A(00):1-9. https:// doi.org/10.2106/JBJS.20.00775

23. Marasco G, Nardone OM, Maida M, Boskoski I, Pastorelli L, Scaldaferri F, Italian Association of Young G, Endoscopist (2020) Impact of COVID-19 outbreak on clinical practice and training of young gastroenterologists: a European survey. Dig Liver Dis. https://doi.org/10.1016/j.dld.2020.05.023

24. Bambakidis NC, Tomei KL (2020) Editorial. Impact of COVID-19 on neurosurgery resident training and education. J Neurosurg 1-2. https://doi.org/10.3171/2020.3.JNS20965

25. Rosen GH, Murray KS, Greene KL, Pruthi RS, Richstone L, Mirza M (2020) Effect of COVID-19 on urology residency training: a nationwide survey of program directors by the Society of Academic Urologists. J Urolo 101097JU0000000000001155. https://doi.org/10.1097/JU.0000000000001155

26. Pennington Z, Lubelski D, Khalafallah AM, Ehresman J, Sciubba DM, Witham TF, Huang J (2020) Letter to the editor "Changes to neurosurgery resident education since onset of the COVID-19 pandemic". World Neurosurg. https://doi.org/10.1016/j.wneu.2020.05. 139

27. Ramos O, Mierke A, Eastin M, Morrison M, Wongworawat DM, Danisa O (2020) COVID-19 pandemic and the implications for orthopaedic and neurosurgery residents and fellows on spine rotations. N Am Spine Soc J (NASSJ). https://doi.org/10.1016/j.xnsj. 2020.100006

28. Kogan M, Klein SE, Hannon CP, Nolte MT (2020) Orthopaedic education during the COVID-19 pandemic. J Am Acad Orthop Surg 28(11):e456-e464. https://doi.org/10.5435/JAAOS-D-2000292 
29. Palan J, Roberts V, Bloch B, Kulkarni A, Bhowal B, Dias J (2012) The use of a virtual learning environment in promoting virtual journal clubs and case-based discussions in trauma and orthopaedic postgraduate medical education: the Leicester experience. J Bone Joint Surg Br Vol 94(9):1170-1175. https://doi.org/10.1302/0301620X.94B9.28780

30. Stambough JB, Curtin BM, Gililland JM, Guild GN 3rd, Kain MS, Karas V, Keeney JA, Plancher KD, Moskal JT (2020) The past, present, and future of orthopedic education: lessons learned from the COVID-19 pandemic. J Arthroplast. https://doi.org/10.1016/j. arth.2020.04.032
31. Pedowitz RA, Marsh JL (2012) Motor skills training in orthopaedic surgery: a paradigm shift toward a simulation-based educational curriculum. J Am Acad Orthop Surg 20(7):407-409. https://doi. org/10.5435/JAAOS-20-07-407

32. Scarlat MM, Quaile A, Waddell JP (2020) Conflicts, military medicine and war casualties in International Orthopaedics. Int Orthop 44(1):1-2. https://doi.org/10.1007/s00264-019-04466-z

Publisher's note Springer Nature remains neutral with regard to jurisdictional claims in published maps and institutional affiliations. 